\title{
Espacio y onomástica en El doble de F. M. Dostoievski
}

\begin{abstract}
Alejandro Ariel González ${ }^{1}$
Resumen: Durante más de un siglo, y por curioso que parezca, los diferentes abordajes y estudios de El doble (1846), tanto en Rusia como en Occidente, dejaron sistemáticamente de lado el espacio urbano en el que transcurren los hechos. Eso a pesar de que Fiódor Dostoievski es muy preciso a la hora de situar cada uno de los acontecimientos de la trama. El presente artículo aborda el subtexto histórico y simbólico deEl doble deteniéndose en dos aspectos: el espacio narrativo y la semántica del nombre propio del protagonista.
\end{abstract}

Palabras clave: Espacio narrativo, onomástica, subtexto.

Abstract: For over a century, and funny as it may seem, the different insights and research into The double(1846), both in Russia and in the West, have systematically left aside the urban space where events take place. Even though Fedor Dostoevsky is very accurate in locating each of the events in the plot, Saint Petersburg was merely regarded as a setting for the action. This article deals with the historical and symbolic subtext of The Double focusing on two aspects: narrative space and semantic of the main character's name.

Keywords : Narrative space, onomastics, subtext

\section{San Petersburgo, de marco a coautor}

La referencia topográfica constituye un rasgo característico de la poética misma de las obras de Dostoievski. El lector pierde mucho si no conoce los lugares donde transcurre la acción de sus obras.

DMITRI SERGUÉIEVICH LIJACHIOV

Durante más de un siglo, y por curioso que parezca, los diferentes abordajes y estudios de El doble, tanto en Rusia como en Occidente, dejaron sistemáticamente de lado el espacio urbano en el que transcurren los hechos. A pesar de que Dostoievski es

\footnotetext{
${ }^{1}$ Sociólogo y especialista en Rusia, donde residió entre 2005 y 2014. Se dedica a la traducción desde 2003. Ha publicado artículos en Rusia, Argentina, Brasil y México sobre teoría social, traducción y literatura rusa (en particular Dostoievski). Ha ganado premios de ensayo, literatura y traducción en Argentina y en Rusia. Participa frecuentemente en congresos y conferencias internacionales de eslavística y traducción. Forma parte del programa Lectura Mundi-SEPTeSA de la Universidad Nacional de San Martín, es Pesidente de la Sociedad Argentina de Dostoievski y Docente de las Maestrías de Literaturas Comparadas y Estudios Literarios de la Facultad de Filosofía y Letras de la Universidad de Buenos Aires (UBA). E-mail: alexgon80@hotmail.com
} 
muy preciso a la hora de situar cada uno de los acontecimientos de la trama, San Petersburgo era tomada apenas como el marco de la acción. Corresponde a G. A. Fiódorov (1974) el mérito de indagar en la simbología urbana puesta en juego en $E l$ doble. ${ }^{2}$ Creemos que esta línea de investigación abre perspectivas interesantes para toda aquella persona proclive a la lectura profunda. En lo siguiente, vamos a apoyarnos en sus trabajos.

La San Petersburgo que emerge de las páginas de El doble es, por así decir, el "negativo" de la representación habitual de la ciudad. Si ya El jinete de bronce, de Pushkin, introducía un elemento de ambigüedad en el tratamiento de San Petersburgo hasta entonces solo mostrada en sus aspectos positivos-, será con El doble que emergerá una ciudad sin resplandor, oscura, alejada del tema imperial y ajena a las ambiciones y aspiraciones de los zares. En efecto, en El doble son significativas las ausencias y las omisiones: no se menciona a Pedro el Grande ni la estatua ecuestre de Falconet; tampoco vemos el río Nevá ni el Palacio de Invierno, residencia del zar. Es decir, no vemos a San Petersburgo desde esa «fachada» que permitió crear toda una simbología urbana. Dostoievski elige calles periféricas y el río Fontanka, cuartos pequeños, lúgubres, oficinas estatales en penumbras, funcionarios de rango medio y bajo que pululan por pasillos, escaleras, tabernas. En esa elección podemos leer una postura: el legado de Pedro el Grande, lejos de toda magnificencia, se reduce a la existencia de un aparato burocrático que parece vivir por sí solo, alimentado por funcionarios grises que no tienen más ambición que la de ascender en la escala jerárquica ${ }^{3}$. Veamos más de cerca esta cuestión. La vida de Goliadkin gira en torno a dos grandes centros: el puente Izmáilovski, donde vive Berendéiev, y la calle Shestilávochnaia (hoy Maiakóvskogo), donde se halla su humilde cuarto. Entre ambos se extiende el río Fontanka. Surge la pregunta: ¿por qué precisamente ese es el lugar escogido por Dostoievski? Si de lo que se trataba era de ambientar la historia en lugares secundarios, periféricos, bien podía haber elegido otro. No obstante, el eje es puente Izmáilovski - calle Shestilávochnaia. ¿Cabe pensar que algo propio de ese paisaje atrajo al escritor? Como el lector quizás no esté familiarizado con la geografía de San Petersburgo, creemos que el modo más gráfico de seguir adelante es recurriendo a un mapa de la ciudad tal como esta lucía a mediados del siglo XIX.

\footnotetext{
2 Cf. G. A. Fiódorov, "Peterburg Dvoinika" [1974], "Sankt-Peterburg. God 1846" [1991] en G. A. Fiódorov, Moskovskii mir Dostoevskogo. Iz istorii russkoi judozhestvennoi kulturi XX veka, Moscú, Izdatelstvo Iaziki slavianskoi kulturi, 2004. En rigor, G. A. Fiódorov retoma la tradición abierta por N. P. Antsíferov con sus obras Dusha Peterburga (1922), Peterburg Dostoevskogo (1923) y Bil $i$ mif Peterburga (1924), dedicadas a explorar la semiótica urbana y su imbricación con los textos literarios. Dicha tradición sería luego ampliada con los trabajos de V. N. Toporov (Peterburg $i$ "Peterburgskii tekst russkoi literaturi”, 1982), I. M. Lotman (Simvolika Peterburga i problemi semiotiki goroda, 1984) y D. S. Lijachiov (Dostoevskii v poiskaj realnogo i dostovernogo, 1984).

${ }^{3}$ Cf. Gary Rosenshield, «Deconstructing The Bronze Horseman: Dostoevsky, The Double, and the Pushkinian Legacy on Madness», en Gary Rosenshield, Pushkin and the genres of madness: the masterpieces of 1833, Madison, University of Wisconsin Press, 2003.
} 


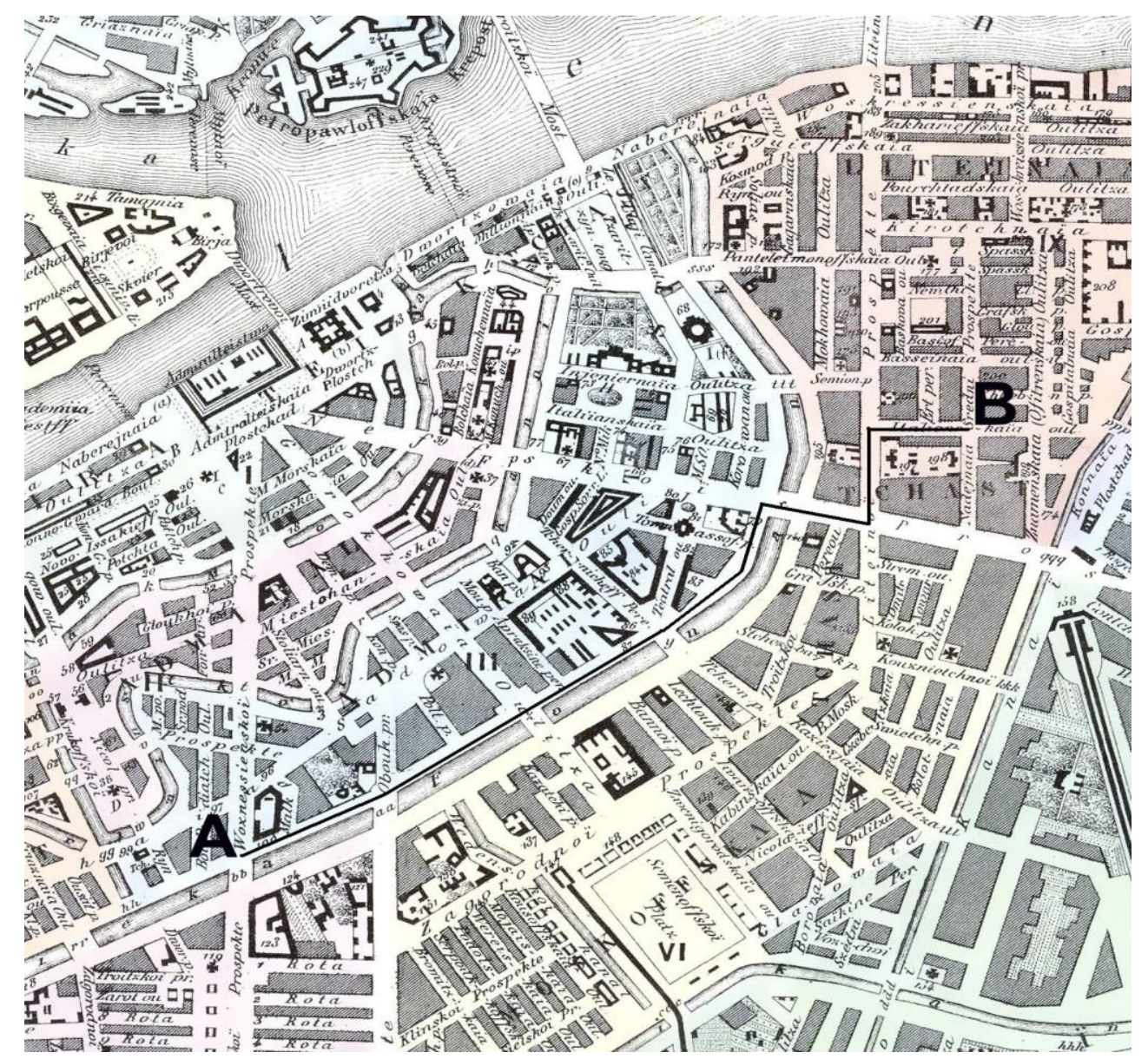

Mapa de San Petersburgo hacia 1845. Entre "A" y "B" hemos trazado el itinerario de Goliadkin.

Como puede verse, el río Fontanka, dada su situación espacial, constituía una suerte de "retaguardia" o "patio trasero" de aquella "fachada" tan ensalzada por poetas y admirada por extranjeros; era a la vez como un río Nevá en pequeñas proporciones, lo cual, también será explotado por Dostoievski. Además, en aquel tiempo trazaba el límite de la ciudad (hoy está integrado en el centro histórico).

Provistos de nuestro mapa, acompañemos a Goliadkin en el camino que recorre aquella fatídica noche en la que encuentra a su doble (capítulo V).

En todas las torres de Petersburgo que marcan y dan las horas sonaron las doce de la noche cuando el señor Goliadkin, fuera de sí, corría en dirección al muelle del río Fontanka, cerca del puente Izmáilovski, para ponerse a salvo de los enemigos [...].

Así, cual preámbulo, se abre la larga escena en la que el doble hará su fantástica aparición. Recordemos las palabras de Bajtín: “[Dostoievski -A. G.] siempre muestra al hombre en el umbral de una última decisión, en su momento de crisis y de cambio inconcluso -y no predeterminado- en su alma". ${ }^{4}$ Y más adelante, analizando la poética

\footnotetext{
${ }^{4}$ M. M. Bajtín, Problemi poetiki Dostoevskogo [1963], en Sobranie sochinenii v 7 tomaj, Moscú, Izdatelstvo Russkie slovari, 2002, tomo VI, p. 72.
} 
de Crimen y castigo y el papel fundamental de San Petersburgo en ella, especifica: "Umbral, vestíbulo, corredor, descanso de escalera, escalera, escalones, puertas abiertas a la escalera, portones y, fuera de esto, la ciudad: plazas, calles, fachadas, tabernas, antros, puentes, canales". 5

Aquí el "umbral", la "intersección" es temporo-espacial. Advirtamos: doce de la noche. Goliadkin llega al muelle, a la orilla del río, cerca del puente Izmáilovski (en nuestro mapa, punto A). Comienza a caminar hacia el noreste, remontando la ribera derecha del Fontanka (cuyas aguas bajan desde el Nevá). Para llegar a su domicilio bordeará el Fontanka, lo cruzará en el puente Ánichkov, que es parte de la Avenida Nevski, seguirá por esta hasta la esquina de la calle (hoy avenida) Litéinaia, doblará a la izquierda y seguirá hasta la calle Italiánskaia (hoy Zhúkovskogo), girará a la derecha y llegará luego a su edificio sobre la calle Shestilávochnaia (punto B). Insistimos, es Dostoievski quien indica con detalle este recorrido. ¿Qué hay (había) en esta parte de la ciudad que tan bien se avenía a la intención artística del autor?

En los años 1760 comienzan a construirse en San Petersburgo puentes fijos y de piedra que venían a sustituir a los precarios puentes de madera -sobre pilotes y flotantes- con los que hasta entonces contaba la ciudad. En los años 1780 fueron construidos, a lo largo del Fontanka, siete puentes idénticos, con torres, cúpulas y pesadas cadenas que levantaban el tramo central (de madera) para que pasaran embarcaciones. En la historia y en las crónicas de San Petersburgo se habla de los "siete puentes gemelos". Eran (desde el Nevá): Simeónovski (hoy Belinski), Ánichkov, Chernishov (hoy Lomonósov), Semiónovski, Obújovski, Izmáilovski y Staro-Kalinkin. En la actualidad, solo dos de esos puentes conservan su aspecto original: Chernishov y Staro-Kalinkin (parcialmente).

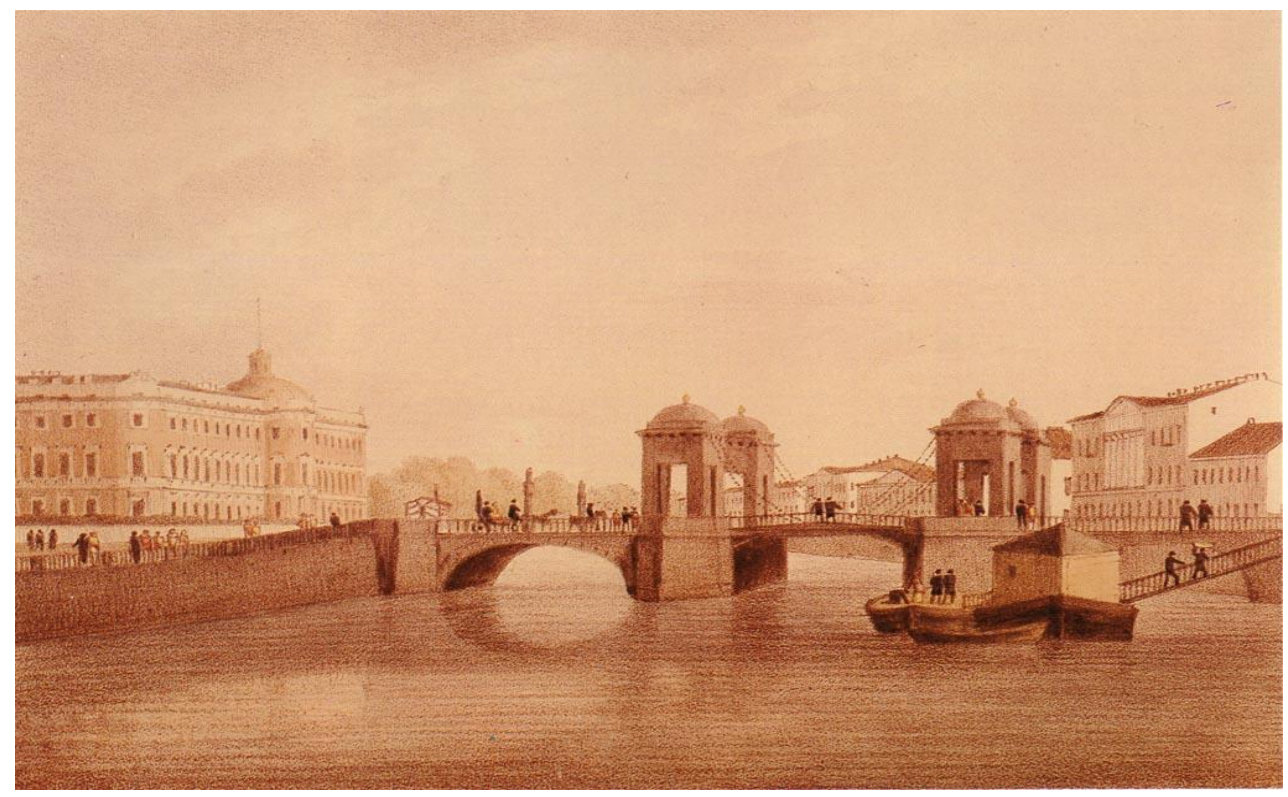

Antiguo puente Simeónovski. Litografía de A. E. Martínov (aprox. 1820). Museo Ruso.

\footnotetext{
${ }^{5}$ Ibíd., p. 192.
} 


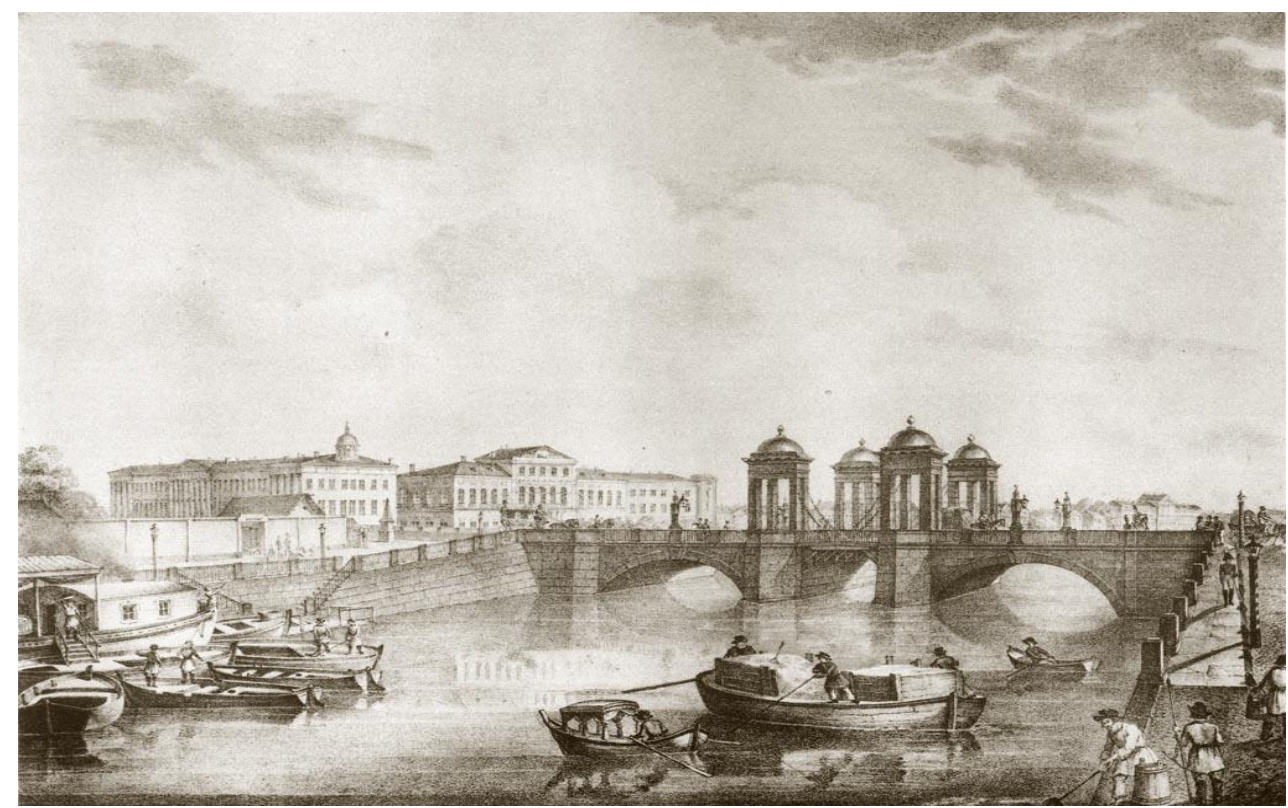

Antiguo puente Obújovski. Litografía de K. P. Beggrov (1823). Museo Ruso.

Goliadkin parte desde el puente Izmáilovski en dirección al río Nevá. En medio de esa noche tenebrosa y hostil sale a su paso, una y otra vez, la misma y sombría silueta de esos dos pares de columnas erigidas sobre las aguas: Obújovski, Semiónovski, Chernishov. Tres puentes gemelos que coinciden con las tres instancias de aparición del doble. Obújovski ("le pareció que alguien, en ese mismo instante, estaba allí junto a él, a su lado, también acodado sobre la baranda del muelle”), Semiónovski ("vio ante sí a un transeúnte que venía a su encuentro, quizás, al igual que él, también retrasado por algún motivo"), y diez minutos después, Chernishov ("Otra vez ante él, a veinte pasos, emergió la negra silueta de un hombre que iba a su encuentro [...] el señor Goliadkin conocía cabalmente a ese hombre, sabía cómo se llamaba y cuál era su apellido"). ¿Casualidad? Difícilmente, tratándose de Dostoievski. Ninguna otra región de San Petersburgo se ajustaba tan bien al tema del relato. Decimos "se ajustaba", cuando en realidad es la misma ciudad la que desarrolla el tema. ${ }^{6}$ Esto resultará aún más evidente si seguimos a Goliadkin en su derrotero.

[...] recobró algo sus sentidos y de repente se lanzó a correr con todas sus fuerzas sin mirar atrás [...] Al fin, el señor Goliadkin acortó un poquito el

\footnotetext{
6 “La precisión topográfica era en él [Dostoievski $-A$. G.] más bien un método de creación que un objetivo artístico [...] Dostoievski no 'componía' la realidad, sino que 'anexaba' a ella sus obras. Tomaba un hecho real, un lugar real, un encuentro casual, una noticia en el periódico sobre algún acontecimiento, un reporte sobre un proceso judicial y le añadía a todo eso una continuación; poblaba con su imaginación una calle que había visto, abría mentalmente puertas de departamentos verdaderamente existentes, ingresaba en antiguos sótanos, creaba biografías para los transeúntes reales que cruzaba por la calle [...] La referencia al lugar de la acción parece decir mucho de aquello que Dostoievski no alcanza a contar al lector, pero que era bien conocido por sus contemporáneos. Dostoievski no escribía para aquellos que vivirían muchos años después, sino para sus contemporáneos, y muy a menudo, para los petersburgueses". D. S. Lijachiov, "Dostoevskii v poiskaj realnogo i dostovernogo", en D. S. Lijachiov, Literatura, realnost, literatura, Leningrado, Izdatelstvo Sovietskii Pisatel, 1984, pp. 55, 57 y 70.
} 
paso para cobrar aliento, miró de prisa en torno suyo y vio que, sin advertirlo, había recorrido ya todo su camino a lo largo del Fontanka, cruzado el puente Ánichkov, seguido una parte de la Nevski y ahora estaba en la esquina de la Litéinaia.

Hacia 1845, cuando Dostoievski escribe El doble, el puente Ánichkov, uno de los más emblemáticos de la ciudad, ya no lucía como sus otros seis "hermanos gemelos". La Avenida Nevski había debido ser ensanchada al ritmo del crecimiento urbano, y en 1841 el puente fue reconstruido y rediseñado. Sin embargo, prolongaba a su modo -y de manera bastante elocuente- el tema de la duplicidad. Conviene repasar un poco la historia: hacia fines de 1832 y principios de 1833, el zar Nicolás I encarga al escultor Piotr Kárlovich Klodt la confección de dos grupos de esculturas para adornar el malecón del Almirantazgo, a orillas del Nevá. Los modelos propuestos por el escultor fueron aprobados, pero, hacia 1835, Nicolás I, que supervisaba el proyecto de decoración, decidió colocar jarrones en el lugar asignado a las estatuas. Klodt, al corriente del plan de reconstrucción del puente Ánichkov, sugirió entonces la idea de instalar las esculturas en el puente, sobre pedestales. La idea halló buena acogida en el zar y, el 20 de noviembre de 1841, el puente con las esculturas de Klodt fue solemnemente inaugurado (en enero de 1842 se abrió a la circulación). El evento gozó de una enorme trascendencia. Un testigo escribió: "El nuevo puente Ánichkov deja maravillados a todos los habitantes de Petersburgo. La gente se reúne en multitudes para admirar la asombrosa proporción de todas las partes del puente y los caballos, los cuales, nos atrevemos a decir, son únicos en el mundo [...] Ninguna otra obra de San Petersburgo ha causado tanta impresión en los habitantes de la ciudad como el puente Ánichkov". Tengamos presente este impacto y la centralidad que ocupaba este prodigio arquitectónico en las representaciones colectivas de los petersburgueses de la época. El nuevo puente lucía suntuoso, los pilares y los arcos estaban revestidos en granito, las barandas eran de hierro colado y estaban ornamentadas con pares alternados de caballos marinos y rusalkas (sirenas de la tradición eslava).

Ahora bien, ¿cuáles eran esas esculturas sobre el puente? Los Dioscuros. Sendas estatuas de Castor y Pollux se erguían sobre las aguas del Fontanka en su representación habitual, domando caballos. Recordará el lector quiénes eran los Dioscuros en la mitología griega: hijos gemelos de Zeus (según sea la versión) y de Leda, hermanos de Helena de Troya y Clitemnestra; en latín eran conocidos como Gemini. El tema, repetimos, lo brinda la misma ciudad. Pero hay más. Las dos estatuas en bronce de Castor y Pollux fueron colocadas sobre la derecha del puente (desde el Nevá), y sendas copias de las mismas (en yeso) fueron instaladas sobre la izquierda. Desde 1841 hasta 1844 esos dos pares de esculturas (originales y copias) permanecieron sobre el puente. Su disposición era cruzada: las estatuas iguales estaban en diagonal. Entre 1844 y 1846 convivieron, finalmente, cuatro esculturas en bronce, hasta que Nicolás I decidió enviar 
un par de regalo a Fernando I de las dos Sicilias. Entre 1846 y 1850, otra vez, un par de esculturas en yeso aguardaba la fundición de un nuevo par en bronce, pero eso ya no sucedió. Klodt decidió componer un único tema con cuatro esculturas y, en lugar de dos copias de las precedentes, continuó el motivo de la doma de caballos con dos estatuas diferentes. Así es como luce el puente Ánichkov hasta nuestros días.

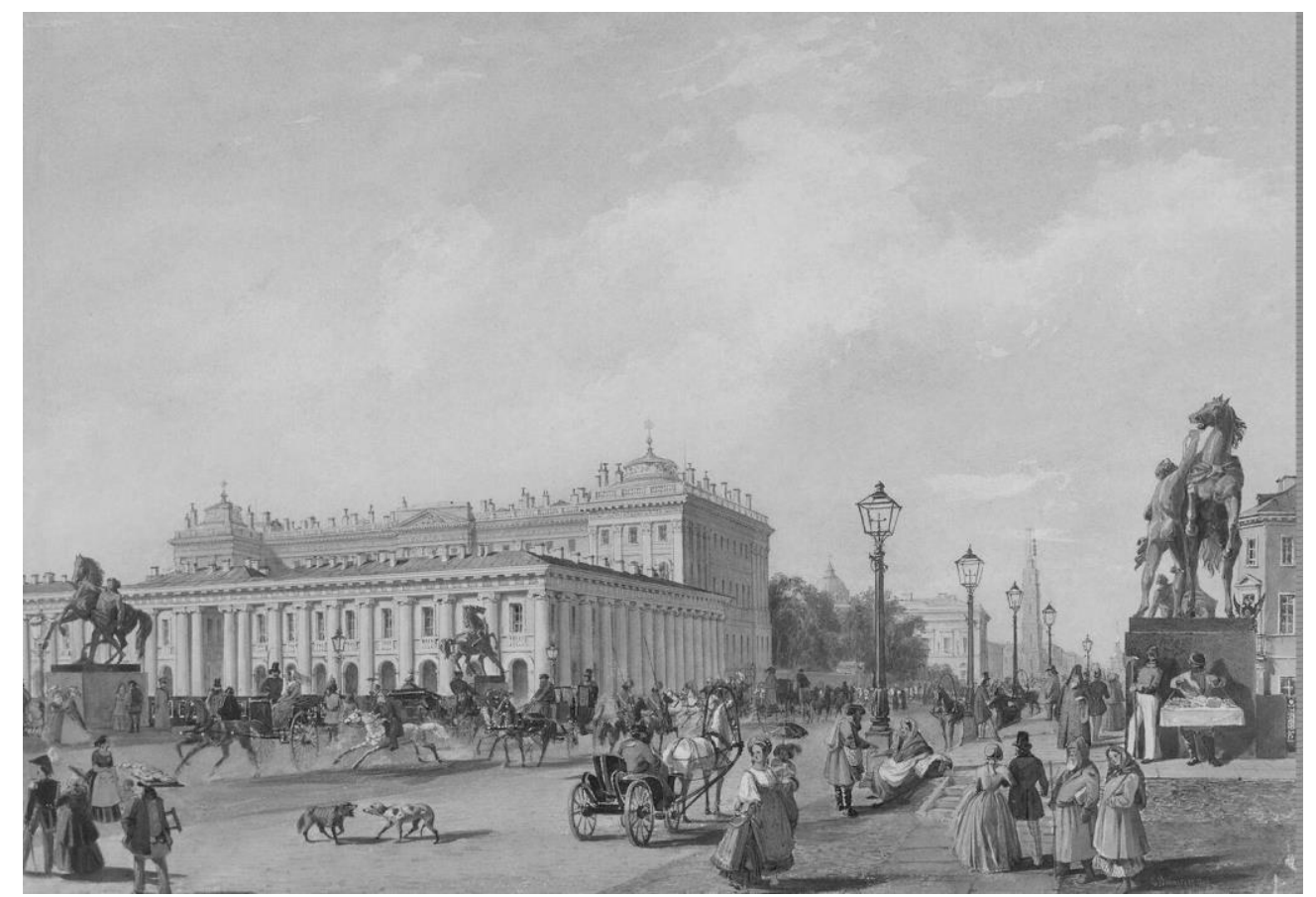

Puente Ánichkov en 1847 (las esculturas de los Dioscuros del lado derecho reproducen en diagonal las del lado izquierdo). Litografía de L. Bonshtedt. Museo Hermitage.

Y bien, justamente ese puente es el que atraviesa en su carrera el señor Goliadkin. Tres puentes gemelos ya quedaron atrás, tres veces ya apareció su doble. Ahora Goliadkin pasa junto a los gemelos Dioscuros, toma la calle Litéinaia y pronto verá a su sosías... pero antes Dostoievski introduce un detalle:

Un perrito extraviado, todo mojado y transido de frío, se pegó al señor Goliadkin y empezó a correr junto a él, de costado, apurado, con el rabo y las orejas bajas, echándole de tanto en tanto una mirada tímida y despierta. Una idea lejana, ya largo tiempo olvidada - el recuerdo de una circunstancia ocurrida antaño-, acudió ahora a su mente, golpeaba como con un martillito su cabeza, lo disgustaba y no lo dejaba en paz. “¡Ay, qué perrito detestable!”-murmuró el señor Goliadkin, sin comprender él mismo lo que decía.

A primera vista, en una lectura rápida, este episodio puede pasar desapercibido. No parece guardar, en principio, relación alguna con la situación presente de Goliadkin. ¿Cuál puede ser esa “idea largo tiempo olvidada"? ¿Y por qué disgusta tanto a 
Goliadkin, que termina maldiciendo al animal? Dostoievski aquí está explotando al máximo los tópicos literarios vinculados a la duplicidad humana, al tratamiento fantástico del doble. Momentos antes de volver a encontrar a su desconocido (que ahora caminará en su mismo sentido, hacia su casa) aparece un perro. La literatura tiene un antecedente de ello, muy bien conocido por Dostoievski: Fausto, de Goethe. La escena en cuestión es la de la aparición de Mefistófeles, nada menos.

FAUSTO: ¿Ves aquel perro negro que anda vagando por entre los trigos y rastrojos?

WAGNER: Mucho rato ha que le veía, y no me ha parecido que tenga importancia alguna.

FAUSTO: Obsérvalo bien. ¿Por quién tomas a ese animal?

WAGNER: Por un perro de aguas que, a su manera, se empeña con porfía en seguir las huellas de su amo.

FAUSTO: ¿Adviertes cómo, describiendo anchas espirales, corre en derredor nuestro y cada vez más cerca? Y, si no me engaño, deja a su paso, a modo de torbellino, un rastro de fuego.

WAGNER: No veo sino un perro de aguas negro. Eso bien podría ser una ilusión de vuestros ojos.

FAUSTO: Paréceme que tiende sutiles lazos mágicos alrededor de nuestros pies, para formar luego una atadura.

WAGNER: Véole inseguro y temeroso saltar en torno nuestro porque, en lugar de su amo, ve dos desconocidos.

FAUSTO: El círculo se va estrechando; ya está cerca.

WAGNER: Bien ves que aquello es un perro y no un fantasma [...]. ${ }^{7}$

Como sabemos, en Fausto ese perro negro es el demonio. El doble de Goliadkin traza los mismos movimientos circulares; primero se anuncia como una voz, luego sale dos veces a su encuentro, ahora caminará junto con Goliadkin. ${ }^{8}$ Toda la atmósfera del

\footnotetext{
${ }^{7}$ Johann Wolfgang Goethe, Fausto, San Juan de Puerto Rico, Biblioteca de Cultura Básica, 2002, pp. 7677. Dostoievski tenía muy presente este detalle, así lo confirma una de sus obras posteriores, Humillados y ofendidos, en la que el narrador, refiriéndose al estrafalario perro de Smith, dice: "Ese desgraciado perro también parecía tener ochenta años; sí, sin falta debía ser así. Primero, era en apariencia tan viejo como no suele serlo ningún perro, y, segundo, ¿por qué en cuanto lo vi acudió de inmediato a mi cabeza la idea de que ese perro no podía ser como los demás, que era un perro extraordinario, que sin falta debía haber en él algo fantástico, de hechicería, que quizás era un Mefistófeles cualquiera con forma de perro, y que su destino, de alguna forma misteriosa y desconocida, estaba ligado al destino de su amo?". Pólnoie Sobranie Sochinenii v 30 tomaj, tom 3, p. 171.

${ }^{8}$ Es probable también que esta asociación le llegara a Dostoievski a través de Gógol, y en relación directa con el tratamiento grotesco del doble. En La nariz, cuando Kovaliov va a poner un anuncio en el periódico para encontrar su nariz, tiene lugar el siguiente diálogo entre el funcionario del diario y el protagonista:

-La semana pasada hubo un caso semejante. Vino un funcionario, igual que ha venido usted ahora, con una nota que le salió dos rublos con setenta y tres kopeikas, y todo el anuncio consistía en que se había escapado un perro de aguas de pelo negro. Al parecer, eso no tenía
} 
capítulo V es fantástica: intemperie, tinieblas, puentes gemelos, esculturas gemelas, figuras mitológicas, fuerzas ajenas y hostiles, reminiscencias literarias, evocaciones demoníacas. Pero acompañemos a Goliadkin más allá.

Por fin vio a su desconocido en la esquina de la calle Italiánskaia. Solo que ahora el desconocido ya no caminaba a su encuentro, sino en el mismo sentido, y corría, también, varios pasos delante de él.

El itinerario del protagonista sigue siendo descrito pormenorizadamente. Calle Litéinaia e Italiánskaia. Esa esquina. No otra. Hay allí un hospital, el Mariinski, que hoy sigue funcionando, y que ya entonces ocupaba media manzana. Nada habría de extraño en él, si no fuera por la existencia de otro hospital Mariinski, en Moscú, construido al mismo tiempo y bajo los mismos planos del arquitecto italiano Giacomo Quarenghi. Ambos hospitales gemelos fueron inaugurados con apenas un año de diferencia, $1805 \mathrm{y}$ 1806 respectivamente. Fueron los dos primeros hospitales para pobres, gratuitos, en la historia de Rusia. Dostoievski, evidentemente, apela a su experiencia vital, a su propia biografía. En la esquina de Litéinaia e Italiánskaia se encuentra el ala izquierda del hospital. En la misma ala izquierda, pero del Mariinski de Moscú, ocupaba un departamento el médico Mijaíl Andréievich Dostoievski, padre de Fiódor Mijáilovich; el escritor nació en 1821 en el ala derecha y vivió en la izquierda, ${ }^{9}$ con su familia, hasta 1837, cuando se trasladó a San Petersburgo.

nada de malo, ¿verdad? Pero acabó siendo un pasquín: el perro no era otro que el tesorero de no recuerdo qué administración.

-Pero el anuncio que yo hago no se refiere a ningún perro, sino a mi propia nariz, cosa que equivale casi a mí mismo.

${ }^{9}$ Hoy funciona allí el Departamento-Museo Dostoievski de Moscú. 


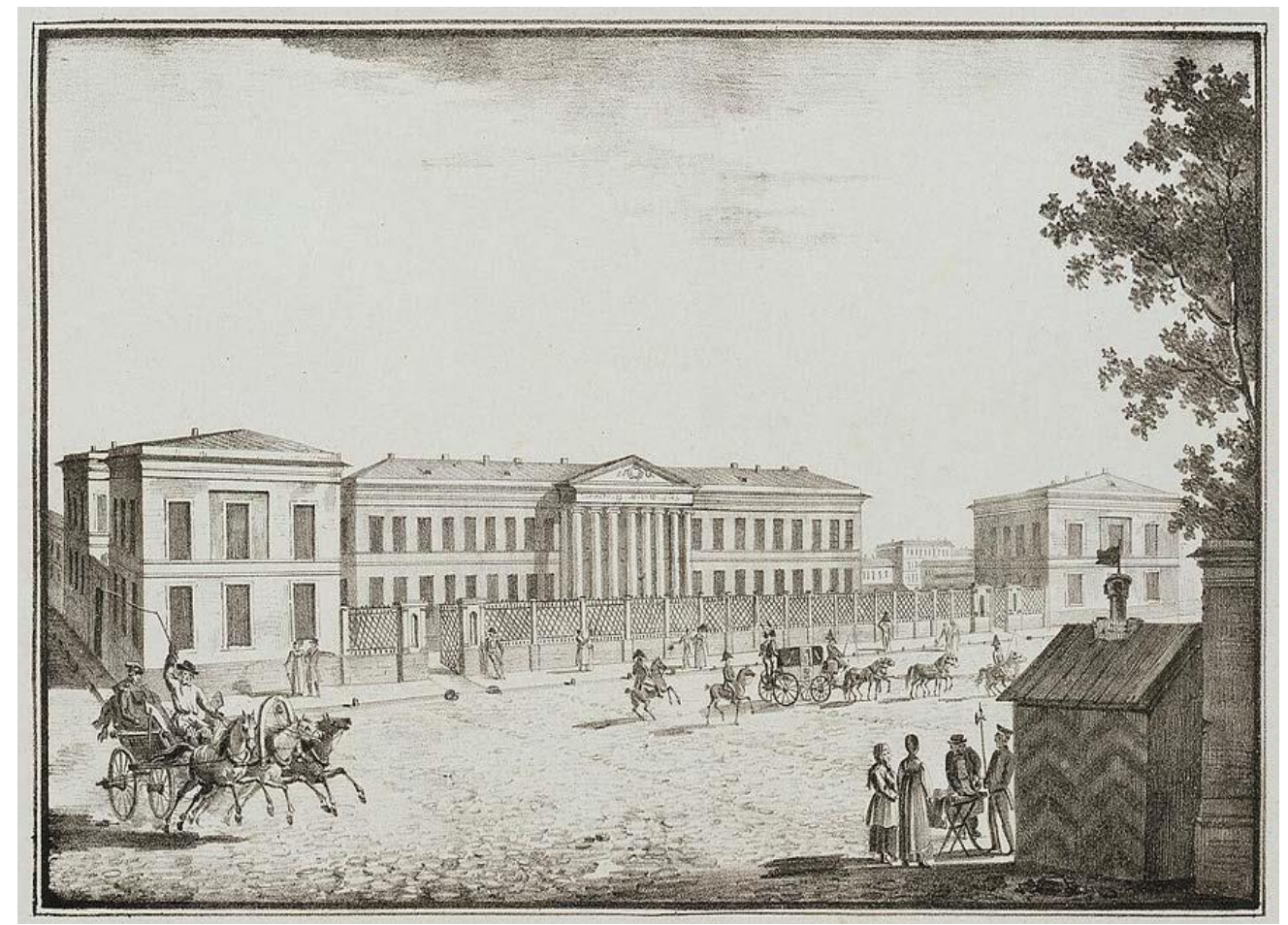

Hospital para pobres Mariinski de San Petersburgo (aprox. 1820). Litografía de artista desconocido.

Es en esa esquina donde Dostoievski quiere que Goliadkin vuelva a toparse con su doble. Si la ciudad puede pensarse como texto -idea motriz de los estudios culturales de Georg Simmel y Walter Benjamin-, entonces hay que concluir que Dostoievski era un lector privilegiado.

Mencionamos antes que el río Fontanka constituía el límite de San Petersburgo. Goliadkin lo recorre desde el puente Izmáilovski hasta el puente Ánichkov. En ese entonces, la toponimia añadía una carga simbólica al carácter fronterizo de la zona. Desde la fundación de San Petersburgo, el territorio que se extendía sobre la margen derecha del Fontanka era llamado "Petersbúrgskaia storoná" ('lado de Petersburgo'), mientras que el territorio que se abría sobre la margen izquierda era conocido como "Moskóvskaia storoná" ('lado de Moscú'). De esta parte, San Petersburgo; de la otra, Moscú. Seis puentes gemelos las unen, y el puente más céntrico de la ciudad despliega el motivo de los Dioscuros. ¿Había mejor lugar para escribir sobre el doble? ¿Cabe, en un caso así, hablar de la ciudad meramente como marco de la acción? ¿O, reintegrándole toda su dignidad, hay que considerarla "coautora" de la obra? Creemos que la respuesta a estas preguntas emerge de las páginas precedentes.

\section{Onomástica}

Un recurso característico en la literatura rusa es asignar a los personajes nombres, y sobre todo apellidos, cargados semánticamente. Desde luego, no todo escritor ni toda obra se valen de dicho recurso, pero su uso está muy extendido en las creaciones literarias. Hasta donde sabemos, la lengua francesa aún no tiene, como la 
inglesa o la rusa, una palabra afianzada para referirse a este fenómeno. En inglés existe charactonym cuando el personaje es literario, y aptronym cuando la persona es real. Permitámonos entonces valernos de una versión castellanizada del concepto: caractónimo.

$\mathrm{Si}$ ya en las representaciones populares rusas podían encontrarse caractónimos, es a partir de mediados del siglo XVIII, con dramaturgos como V. I. Lukin y D. I. Fonvizin, que el recurso entra de lleno en la literatura. Desde entonces, fue utilizado inagotablemente por autores de la talla de Pushkin, Griboiédov y A. N. Ostrovski, entre otros. Cabría a Gógol extender y popularizar su uso en la prosa. En el caso de Dostoievski, el procedimiento de atribuir caractónimos a sus personajes atravesará toda su obra.

Los caractónimos pueden denotar los rasgos psicológicos o físicos de un personaje, su actitud hacia los demás, su posición social, su destino, o también la relación del autor con él (paródica, irónica, evocativa, etc.). Este tratamiento de los nombres propios permite al escritor cifrar en la onomástica de sus personajes significados más o menos transparentes, más o menos ocultos. ${ }^{10}$

Veamos qué sucede en $E l$ doble, porque, otra vez, mediante el análisis de esta dimensión accederemos a niveles más hondos del texto, a las representaciones que este moviliza y que, a su vez, lo alimentan.

El protagonista se llama Iákov Petróvich Goliadkin. Desandemos ese nombre.

Iákov. Iákov es la forma rusa del nombre bíblico-hebreo Ya'akov, que en francés conocemos como Jacob. Acaso el lector no esté familiarizado con el relato bíblico sobre Jacob en el libro del Génesis; lo resumiremos sucintamente.

Hijo de Isaac y de Rebeca, Jacob es el hermano gemelo de Esaú. Su nombre encierra la palabra "talón", ya que, siendo el menor de los dos gemelos, nació agarrándose del talón del primero. La raíz hebrea que da origen al nombre Ya'akov adquiere en otros pasajes bíblicos el sentido de "retaguardia", "huella", "iniquidad", y forma adjetivos como "insidioso", "falso", “engañoso". Lo habitual, más allá de la etimología, es atribuir a Jacob el papel de suplantador, pícaro, "quien toma la delantera", "quien deja atrás". Jacob lucha con Esaú ya en el seno materno, provocando la desazón de Rebeca. Yahvé, ante la consulta de esta, contesta: "Dos pueblos hay en tu vientre, dos naciones que, al salir de tus entrañas, se dividirán. La una oprimirá a la otra; el mayor servirá al menor" (25:21). Jacob justifica reiteradas veces este designio: compra la primogenitura a Esaú por un plato de lentejas; luego, con ayuda de la madre, se hace pasar por Esaú para recibir la bendición paterna, y en general recurre a diferentes tretas y astucias a lo largo de su vida. Dostoievski era un gran conocedor de

${ }^{10}$ No siempre el significado es inmediatamente percibido por el lector; muchas veces, el autor puede estar resolviendo para sí mismo problemas vinculados a la poética del texto, en un plano, por llamarlo así, criptogramático, y decide incluir elementos solo conocidos por él o incluso autobiográficos. Cf. "Eshe raz ob 'umishlennosti' Dostoevskogo", en V. N. Toporov, Peterburgskii tekst, Moscú, Izdatelstvo Nauka, 2009, pp. 453-457. 
la Biblia, una de sus lecturas infantiles, por lo que es imposible atribuir a la casualidad el nombre de pila de Goliadkin. Además, Iákov era y es un nombre muy poco frecuente en Rusia. Así, dos pares de gemelos mitológicos subyacen al relato: Castor y Pollux, por un lado, Jacob y Esaú, por el otro.

Petróvich. En ruso, el segundo nombre de una persona es el patronímico. En el presente caso, Petróvich señala la filiación: "hijo de Piotr" (la forma femenina sería Petrovna). ¿Quién es ese Piotr que ha engendrado a ambos Goliadkin? La historia transcurre en San Petersburgo y, como ya hemos visto, se asienta -aunque críticamenteen los tópicos y en las representaciones literarias de la ciudad de Pedro. Goliadkin es hijo directo del proyecto de Pedro el Grande, de las dos capitales, de la Tabla de rangos, de un sistema burocrático impuesto desde arriba, de una ciudad sin organicidad alguna con la historia y el desarrollo espiritual rusos. ${ }^{11}$ El patronímico Petróvich sitúa en el tiempo y en el espacio a su personaje.

Goliadkin. Este es un buen ejemplo de cómo pueden funcionar los caractónimos en un plano conciente, por un lado, y cómo servir al escritor para componer la obra, por el otro. En ruso, el apellido Goliadkin dispara una serie de asociaciones con palabras referidas a la pobreza, la indigencia, el desamparo, la desnudez, (gol, goli, golish, golitbá). El propio Goliadkin se hace reproches a sí mismo con su apellido:

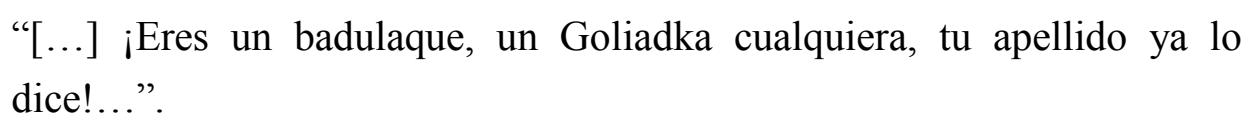

El narrador, con férrea consecuencia, llama al protagonista "señor Goliadkin". Eso sirve a los fines grotescos del relato, toda vez que, en ruso, no es habitual hablar de una persona llamándola exclusivamente por su apellido, y más aún anteponiendo la palabra "señor"; eso es algo en extremo formal y señala un trato distante. Puede verse en ello, también, un contraste que va al fondo de la problemática del personaje: un hombre pequeño, un don nadie, un mero engranaje del sistema pretende ser valorado por su nobleza, honestidad y rectitud; el narrador parece tomar nota de ello en clave irónica. Esto es lo que se ofrece a la percepción del lector.

Ahora bien, si tenemos en cuenta la raíz goliad, podremos ver de dónde abreva Dostoievski para estructurar el relato. Recordemos que los sucesos de El doble se desenvuelven entre dos polos, el departamento de Goliadkin en la calle Shestilávochnaia y el edificio situado junto al puente Izmáilovski, donde tiene su departamento Olsufi Ivánovich Berendéiev. Goliadkin es expulsado dos veces de la casa de Berendéiev, es allí donde sufre el oprobio, y es desde allí donde lo trasladan al manicomio; antes de eso, allí se había decidido negarle el ascenso y él había armado un escándalo. La tensión está cifrada en los términos Goliadkin-Berendéiev... muy similares a los nombres de dos

\footnotetext{
${ }^{11}$ Dostoievski solía referirse a la nobleza ilustrada surgida de las reformas de Pedro el Grande con el epíteto "polluelos del nido de Pedro", palabras tomadas del poema de Pushkin Poltava (1828).
} 
pueblos que habitaron el suelo ruso y que aparecen registrados en Historia del Estado Ruso, de Nikolái Karamzín, los goliadi y los berendéi. ${ }^{12}$ Los goliadi eran una tribu proveniente del Báltico que se instaló en las inmediaciones de la actual Moscú hacia los siglos XI-XII, mientras que los berendéi eran una tribu túrquica, seminómade, que habitó las estepas rusas entre los siglos XI-XIII. Los goliadi provenían del oeste, los berendéi eran orientales. ${ }^{13}$ Entre las distintas leyendas acerca de la fundación de Moscú, existe una según la cual el pueblo de Kuchkovo, futura Moscú, se encontraba entre las aldeas Goliadinka y Berendéievo, habitadas por sendos pueblos. ${ }^{14}$ Este y oeste como polos en la constitución misma de Rusia. La raíz asiática de Berendéiev queda señalada, además, en su nombre de pila, Olsufi. Como vemos, Dostoievski explota a fondo el tema de la duplicidad, de la rivalidad, hurgando en el acervo folklórico y cultural de su nación. Este plano, si bien no es inmediatamente perceptible por el lector, sí nos permite echar luz sobre la concepción misma de la obra, sobre el enfoque del autor y sobre la problemática que este intenta recrear artísticamente.

\footnotetext{
${ }^{12}$ Dostoievski conocía a la perfección la obra del historiador ruso. En una carta escrita a N. N. Strájov en 1870, afirma: "Yo crecí leyendo a Karamzín". Pólnoie Sobranie Sochinenii v 30 tomaj, tom 29 (1), p. 153.

${ }^{13}$ Los berendéi dejaron sus huellas no solo en las crónicas de los siglos XI-XIII, en algunos topónimos asociados a sus creencias (el pantano Berendéievo, sobre el que circulan muchas leyendas, entre ellas una que afirma que allí vivía el mítico zar Berendéi, protagonista de varios cuentos populares rusos) y en artesanías (berendeiki eran juguetes de madera con forma humana y animal tallados cerca del pueblo Berendéievo), sino también en la lengua: el verbo berendérit significaba "golpear", "azotar", "fustigar", y berendit "molestar", "obstaculizar", "disputar", "contrariar" (cf. V. I. Dal, Tolkovi slovar zhivogo velikorusskogo iazika, Moscú, Gosudarstvennoie izdatelstvo inostrannij i natsionalnij slovarei, 1955, tomo 1, p. 83); así quedó registrado en la memoria popular el servicio de los berendéi a los príncipes rusos. Cf. V. N. Zajárov, Sistema zhanrov Dostoevskogo: tipologia i poetika, Leningrado, Izdatelstvo LGU, 1985, pp. 90-91.

${ }^{14}$ Cf. I. M. Sneguiriov, Moskva. Podrobnoie istoricheskoie i arjeologicehskoie opisanie goroda, Moscú, Izdanie A. Martinova, 1865, tomo 1, p. 102. El historiador I. M. Sneguiriov era muy amigo del padre de Dostoievski, y solía frecuentar su casa en Moscú cuando el escritor aún vivía allí.
} 